\title{
Creatine phosphokinase levels in the newborn and their use in screening for Duchenne muscular dystrophy
}

\author{
L. M. DRUMMOND \\ University of Auckland School of Medicine
}

SUMmary The PKU sample, if taken after the 3rd day, is suitable for Duchenne muscular dystrophy screening using creatine phosphokinase (CPK) levels. 101 babies (53 girls and 48 boys) had CPK levels measured on filter paper blood specimens taken by heel prick on the 1st and 4th days of life. The method used was that described by Zellweger and Antonik (1975). The CPK levels were markedly raised on the 1st day of life but by the 4th day they had reduced to within 3 times the upper limit of the normal range for adults. 10000 boys were then screened for Duchenne muscular dystrophy using the PKU sample, and 2 cases were found.

Duchenne muscular dystrophy (DMD) has a reported incidence of 1 in 3600 to 1 in 5600 live male births (Morton and Chung, 1959). It is inherited as an $\mathrm{X}$-linked recessive condition and considered to be genetically lethal in boys as affected people do not reproduce. Calculations show that to maintain the incidence in the population, one-third of new cases with no family history must be fresh mutations. Thus carrier detection is very important for the mother and other female relatives.

The creatine phosphokinase (CPK) level is greatly raised in DMD, sometimes up to $\mathbf{3 0}$ or $\mathbf{4 0}$ times the upper limit of normal for adults. This led Zellweger and Antonik (1975) to suggest that screening of newborn boys for DMD could be carried out by measuring the CPK levels in the dried blood spots normally collected for PKU testing. Any persistent increases would be followed up by serum CPKs, clinical examination, and EMG studies. Early detection of affected infants identifies those mothers and female relatives who should be fully investigated to determine their carrier status before further pregnancies are considered.

The difficulty is that greatly increased CPK levels during the first few days of life have been found in normal newborn babies (Rudolph and Gross, 1966; Bodensteiner and Zellweger, 1971; Gilboa and Swanson, 1976). These increased levels have been attributed to birth trauma but no clear correlation has been established.

Department of Community Health, University of Auckland School of Medicine, New Zealand

L. M. DRUMMOND, research fellow
The aim of this study was (1) to investigate the blood levels of CPK in the neonatal period to establish whether blood taken on the 4th day (as used for PKU testing) would be satisfactory for DMD screening, and (2) to look at DMD screening in a defined population using the PKU specimen.

\section{Methods}

The population sample comprised 101 consecutive live births at St Helen's Hospital, Auckland, New Zealand. Two specimens (dried blood spots from heel pricks) from each infant were assayed; one had been collected within 24 hours of delivery and the other was one routinely taken for PKU screening on the 4th day. The CPK levels were measured using the 'CPK-screen' kitset (Antonik Laboratories) and a Chem-Glow photometer (American Instrument Company).

The CPK activity of the dried blood spot was expressed in arbitrary fluorescent units, in which one unit is equivalent to the meter reading on the Chem-Glow photometer using the 0-100 scale with multiplier switch in position 1. Capillary blood samples from 25 normal adults were collected on filter paper cards and assayed by the standard technique to establish a normal adult range. Data were also recorded about the pregnancy and delivery. Variables considered were birthweight, duration of 1 st and 2nd stages of labour, number of pregnancies, maturity of fetus, and method of delivery.

10000 consecutive liveborn male infants from the Auckland and Northland area were screened 
for DMD using the method described above. The specimens used were the PKU samples collected for the National Testing Centre. Greater than 20 SDs above the batch mean was taken as a positive result. Any positive result was retested, and if it was still greatly raised, a liquid blood sample was requested for a serum CPK estimation, and the baby referred to a paediatrician for evaluation. To investigate the possibility of false-negative results, those specimens with CPK levels outside 3 SDs of the mean of the batch were repeated and, if they remained raised, a 2nd dried blood specimen was requested.

\section{Results}

The CPK levels for all samples taken on days 1 and 4 are shown in Table 1. Analysis of day 4 levels gives a $95 \%$ confidence range of 13-77. This compared with an adult $95 \%$ confidence range of 3-34, and an adult mean of 18.5 with a SD of 7.9. Multiple regression analysis of the variables-birth weight, duration of 1 st and 2nd stages of labour, number of pregnancies, and maturity of fetus-was carried out on the data obtained for those babies who were delivered vaginally ( 93 babies). The correlation coefficient of birthweight with the CPK level was $0.29(\mathrm{P}<0.01)$ and the correlation of the duration of 1st stage labour with the CPK level was $0 \cdot 26$. Multiple regression showed the correlation coefficient of both birthweight and duration of 1st stage of labour with the CPK level to be 0.36 $(0.01<\mathrm{P}<0.05)$.
Table 2 shows levels of CPK found for each method of delivery on days 1 and 4 . This is further illustrated by the Figure. Statistical analysis of the CPK levels on day 1 showed a significant difference between vaginal and vaginal with forceps deliveries $(P<0.01)$, and between elective and emergency caesarean sections $(P<0 \cdot 02)$. There was no significant difference between vaginal deliveries and elective caesarean sections $\left(t_{79}=0 \cdot 6204\right)$.

The 10000 male infants screened showed a wide range of ages at which the PKU specimen was taken. An analysis by days of a random sample of 2217 out of the 10000 is given in Table 3. The CPK levels found on day 2 were not significantly different from those found on day 3 or on day 4. Analysis showed that the negative regression of the CPK values on the age at which the PKU specimen was taken was not statistically significant.

Two greatly raised values were found -1400 and

Table 3 Days on which the PKU specimen was taken

\begin{tabular}{lcc}
\hline Day & No. $(\boldsymbol{n}=2217)$ & Percentage \\
\hline 2 & 8 & $0 \cdot 4$ \\
3 & 493 & $22 \cdot 2$ \\
4 & 866 & $39 \cdot 1$ \\
5 & 527 & $23 \cdot 8$ \\
6 & 137 & $6 \cdot 2$ \\
7 & 78 & $3 \cdot 5$ \\
8 & 34 & $1 \cdot 5$ \\
9 & 23 & $1 \cdot 0$ \\
10 & 15 & $0 \cdot 7$ \\
$11+$ & 36 & $1 \cdot 6$ \\
\hline
\end{tabular}

Table 1 CPK levels on the 1st and 4th days of life

\begin{tabular}{|c|c|c|c|c|c|c|}
\hline & \multicolumn{2}{|c|}{ Boys $(n=48)$} & \multicolumn{2}{|c|}{ Girls $(n=53)$} & \multicolumn{2}{|c|}{ Total $(n=101)$} \\
\hline & Day 1 & Day 4 & Day 1 & Day 4 & Day 1 & Day 4 \\
\hline $\begin{array}{l}\text { Mean } \\
\text { SD } \\
\text { Range }\end{array}$ & $\begin{array}{c}135 \cdot 9 \\
87 \cdot 2 \\
50-410\end{array}$ & $\begin{array}{l}44 \cdot 0 \\
16 \cdot 7 \\
14-97\end{array}$ & $\begin{array}{l}169 \cdot 7 \\
191 \cdot 9 \\
44-1150\end{array}$ & $\begin{array}{l}46 \cdot 3 \\
15 \cdot 6 \\
18-90\end{array}$ & $\begin{array}{l}153 \cdot 6 \\
151 \cdot 7 \\
44-1150\end{array}$ & $\begin{array}{l}45 \cdot 2 \\
16 \cdot 0 \\
14-97\end{array}$ \\
\hline
\end{tabular}

The CPK levels are measured in dried blood spots taken by heel pricks from 101 babies on the 1st and 4th days of life (PKU specimen). Units are arbitrary fluorescent units as described in text.

Table 2 CPK levels on the 1st and 4th days of life for the different methods of delivery of the babies

\begin{tabular}{|c|c|c|c|c|c|c|c|c|}
\hline & \multirow{2}{*}{\multicolumn{2}{|c|}{ Vaginal $(n=77)$}} & \multirow{2}{*}{\multicolumn{2}{|c|}{$\begin{array}{l}\text { Vaginal and } \\
\text { forceps }{ }^{*}(n=16)\end{array}$}} & \multicolumn{4}{|c|}{ Caesarean section } \\
\hline & & & & & Elective & & Emergen & \\
\hline & Day 1 & Day 4 & Day 1 & Day 4 & Day 1 & Day 4 & Day 1 & Day 4 \\
\hline $\begin{array}{l}\text { Mean } \\
\text { SD } \\
\text { Range }\end{array}$ & $\begin{array}{l}136 \cdot 9 \\
142 \cdot 26 \\
44-1150\end{array}$ & $\begin{array}{l}45 \cdot 1 \\
17 \cdot 1 \\
15-97\end{array}$ & $\begin{array}{l}252 \cdot 2 \\
194 \cdot 4 \\
67-810\end{array}$ & $\begin{array}{l}45 \cdot 7 \\
10 \cdot 5 \\
25-67\end{array}$ & $\begin{array}{l}92 \cdot 5 \\
12 \cdot 26 \\
84-110\end{array}$ & $\begin{array}{l}48 \cdot 0 \\
22 \cdot 5 \\
25-75\end{array}$ & $\begin{array}{l}141 \cdot 5 \\
30 \cdot 0 \\
105-178\end{array}$ & $\begin{array}{l}42 \cdot 0 \\
11 \cdot 6 \\
31-58\end{array}$ \\
\hline
\end{tabular}

The CPK levels are measured in dried blood spots taken by heel pricks on the 1st and 4th days of life (PKU specimen). Units are arbitrary fluorescent units as described in text.

*Does not include Wrigley's forceps but does include Ventouse extraction; †all had had previous caesarean sections for difficulties in labour. 


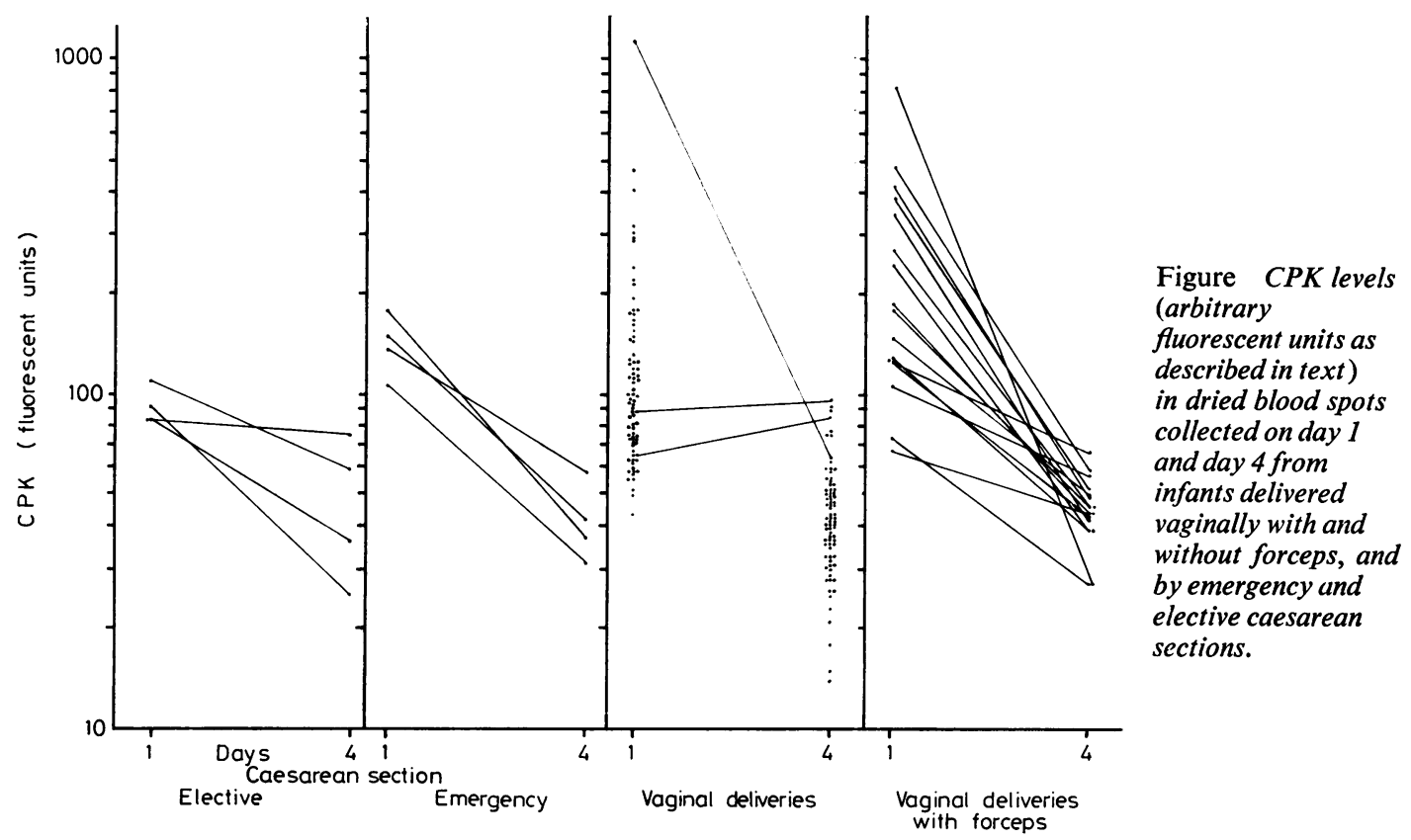

1000 arbitrary units (PKU samples both taken on 4 th day of life). These were respectively 161 and 94 SDs outside their batch means, and liquid blood specimens showed greatly raised serum CPK levels (3044 and 3000 IUs respectively). Physical examination of the two boys was normal. A muscle biopsy confirmed the diagnosis in one and, in both babies, the CPK remains at a greatly raised level. In neither case was there a history of DMD.

In the group of boys with CPK levels $>3$ SDs, one had on day 5 a CPK level between 5 and 6 SDs outside the batch mean but showed a greatly raised CPK at age 6 months. A liquid blood serum CPK level confirmed the greatly raised CPK levels (>2000 IU). On physical exmination the baby is normal and there is a family history of Becker muscular dystrophy.

\section{Discussion}

It has been suggested that the PKU blood sample would be ideal for DMD screening (Zellweger and Antonik, 1975; Beckmann et al., 1976), but others feel that the CPK levels in the immediate neonatal period are too variable to make screening for DMD reliable (Gilboa and Swanson, 1976).

This study confirmed the variability of CPK levels in the 1st 24 hours but by the 4th day even greatly raised levels, as high as those associated with DMD (30 to 40 times the upper limit of normal adult range), had come down to within 3 times the upper limit of the normal adult range. The two highest levels found in two girls-1150 and 810-had reduced to 65 and 27 respectively by the 4th day. This confirms that if the PKU sample is taken after the 3rd day of life, the sample is suitable for DMD screening. As can be seen in the Figure, two CPK levels in the vaginal delivery category actually increased from day 1 to day 4, one from 66 to 86 and the other from 90 to 97 . Both are still within 3 times the upper limit of normal for adults, and the increase can be explained by the error of the method. Triplicate determinations on 53 specimens showed the standard error of one measurement to be $8 \%$. There was no significant difference in CPK levels between boys and girls on either day 1 or day 4 . This would be in agreement with Demos (1971), who found no difference between boys and girls when he excluded boys with preclinical DMD.

The significant difference between CPK levels for normal vaginal deliveries and vaginal deliveries with forceps (not Wrigley's), and that between CPK levels for elective caesarean section and emergency caesarean section are indicative of difficult labour being associated with raised CPK levels. Rudolph and Gross (1966) suggest that hypoxia may damage the muscle cells and thus increase the CPK levels. There may be other causes of damage but the actual mechanism is still unclear. Birthweight and duration of 1st stage labour were the two birth variables that 
had a significant correlation with the CPK level, but this only explained $13 \%$ of the variations in CPK levels.

More significant factors may be the relationship between the configuration of the mother's pelvis and the baby's weight, the strength of uterine contractions and number and duration of periods of hypoxia, but these are very difficult to assess. It is interesting to note that in two cases, maternal pyrexia was present and the infants' CPKs on day 1 were 1150 and 470 . This could be due to a viral infection in the child causing a myositis and thus raised CPK levels.

From the 10000 babies tested, the incidence of DMD in the north of the North Island of New Zealand can be calculated to be 1 in 5000 . This is comparable with the incidence estimated from the pooled data of Morton and Chung (1959) but lower than that found in Germany (Beckmann et al., 1976).

The two DMD cases detected had CPK levels that were much higher than the values found for other infants. It seems there is a clear-cut distinction between 'normal' values for infants and values for preclinical DMD sufferers. However the milder $\mathrm{X}$-linked Becker muscular dystrophy may not be detected by screening at an early age unless the threshold for a positive test is lowered to include a large number of false-positives.

In all three cases of confirmed muscular dystrophy, genetic counselling and carrier detection were offered. There was no family history in either case of DMD. Carrier detection studies were normal for one mother and abnormal for the other, so she intends limiting her family and having her only daughter tested when she reaches child-bearing age. Unfortunately the parents of these two cases of DMD are immigrants to New Zealand and their relatives live in Bermuda and Fiji where the carrier tests are probably not available.

The mother of the child with presumed Becker muscular dystrophy had normal carrier tests but only $60 \%$ of known carriers have raised CPK levels (Skinner et al., 1975). She does not intend limiting her family as the two other affected family members have had only minor disabilities.

It has been suggested that parents wish to know about their child's condition as quickly as possible (Zellweger and Antonik, 1975; Beckmann et al., 1976), but we found in the two DMD cases that this was not so. Information given at a very early stage may not be well received by parents. They are extremely upset and are concerned about their child who looks so normal. At this stage, they are less concerned about the outcome of future pregnancies. It appears that the people who replied to the questionnaires on whether they would like to know early about their child having DMD (Zellweger and Antonik, 1975; Beckmann et al., 1976), are thinking of the practicalities of the situation and not of the emotional problems.

The problem of screening for DMD when there is no known cure has been discussed (British Medical Journal, 1975; Dubowitz, 1976). Gardner-Medwin (1976) points out that genetic counselling given after a DMD case has been detected by screening may not be as effective as predicted. In fact, Roses et al. (1977) suggest that the time and money would be better spent on research into the underlying cause of DMD and better carrier detection. In theory, screening and genetic counselling with carrier detection would reduce the incidence of DMD by preventing the birth of a 2 nd case in a family. However it may be difficult for parents to make informed decisions when they have not adjusted to the fact that their 'normal' son has DMD. It will be interesting to see the long-term effect of screening and genetic counselling for DMD in places where such programmes have been well established.

\section{Conclusions}

1. The PKU sample taken on the 4th day of life can be used for DMD screening as the CPK levels in normal babies are low enough to distinguish from the levels found in DMD.

2. Difficult labours are associated with higher CPK levels.

3. Birthweight is a significant factor in raised levels of CPK, but the actual mechanism is still unknown.

I thank Professor A. M. O. Veale, Dr I. C. T. Lyon, and Mr M. I. Parslow for their help.

This study was supported by The Muscular Dystrophy Research Association of Western Australia, The Medical Research Council of New Zealand, and The New Zealand Neurological Foundation.

\section{References}

Beckmann, R., Scheuerbrandt, G., and Antonik, A. (1976). Erfassung von präklinischer Duchenne-Muskeldystrophie bei Neugeborenen mit dem CPK-screening-test. Monatsschrift für Kinderheilkunde, 124, 658-659.

Bodensteiner, J. B., and Zellweger, H. (1971). Creatine phosphokinase in normal neonates and young infants. Journal of Laboratory and Clinical Medicine, 77, 853-858.

British Medical Journal (1975). Editorial: Screening of the newborn for Duchenne muscular dystrophy. British Medical Journal, 2, 403-404.

Demos, J. (1971). Early diagnosis and treatment of rapidly 
developing Duchenne de Boulogne type myopathy (type DDB I). American Journal of Physical Medicine, 50, 271-284.

Dubowitz, V. (1976). Screening for Duchenne muscular dystrophy. Archives of Disease in Childhood, 51, 249-251.

Gardner-Medwin, D. (1976). Duchenne muscular dystrophy: early diagnosis and screening. Archives of Disease in Childhood, 51, 982-983.

Gilboa, N., and Swanson, J. R. (1976). Serum creatine phosphokinase in normal newborns. Archives of Disease in Childhood, 51, 283-285.

Morton, N. E., and Chung, C. S. (1959). Formal genetics of muscular dystrophy. American Journal of Human Genetics, 11, 360-379.

Roses, A. D., Nicholson, G. A., and Roe, C. R. (1977). Screening for Duchenne muscular dystrophy. Pediatrics, 60, 248-250.

Rudolph, N., and Gross, R. T. (1966). Creatine phospho- kinase activity in serum of newborn infants as indicator of fetal trauma during birth. Pediatrics, 38, 1039-1046.

Skinner, R., Emery, A. E. H., Anderson, A. J. B., and Foxall, C. (1975). The detection of carriers of benign (Becker-type) X-linked muscular dystrophy. Journal of Medical Genetics, 12, 131-134.

Zellweger, H., and Antonik, A. (1975). Newborn screening for Duchenne muscular dystrophy. Pediatrics, 55, 30-34.

Correspondence to Dr L. M. Drummond, University of Auckland School of Medicine, Department of Community Health, Private Bag, Auckland, New Zealand.

Received 24 October 1978 